Eur J Appl Physiol (1989) 59:351-354

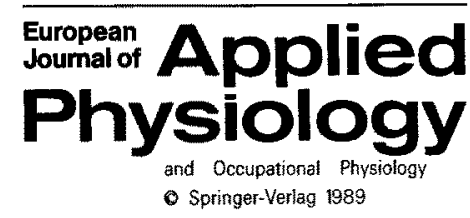

\title{
Strength gains in obese females are unaffected by moderate dietary restriction*
}

\author{
Douglas L. Ballor ${ }^{1}$ and Victor L. Katch \\ Department of Kinesiology, Division of Physical Education, The University of Michigan, Ann Arbor, MI 48 109, USA
}

Summary. This study examined the effects of dietary restriction on strength gains from whole body resistance training. Comparisons were made between diet-restricted $(n=12)$ and non-diet-restricted $(n=10)$ obese women (mean $\pm \mathrm{SD}$, $36.7 \pm 7.0 \%$ fat) undergoing identical 8 -week resistance training regimens. Diet-restricted subjects reduced their dietary intake by $4200 \mathrm{~kJ} /$ day and reduced body mass by $3.9 \mathrm{~kg}$ over 8 weeks. Tenrepetition maximum masses were compared between the groups on biweekly intervals. Results indicated no differences between the groups with respect to the rate or magnitude of strength gains for any of the eight exercises. Significant pre- to post-test increases in strength $(p<0.05)$ were found for all eight exercises. The rate or magnitude of strength gains induced by resistance training does not appear to be affected by moderate dietary restrictions in obese females.

Key words: Diet - Dietary restriction - Resistance training - Strength - Exercise

\section{Introduction}

Dietary restriction can lead to inadequate intake of protein, limited amino acid availability as well as deamination of muscle proteins (Aoki 1981). Decreases in muscle glycogen content have also been noted during periods of dietary restriction (Aoki 1981; Horton 1982). Since lower muscle

Offprint requests to: D. Ballor, Physical Education and Dance, University of Wisconsin-Madison, 2000 Observatory Drive, Madison, WI 53706, USA

* Supported in part by grants from the Rackham Graduate School, The University of Michigan, Universal Gym and Weider Health and Fitness, Inc. glycogen levels have been associated with decreased muscle contraction force (Jacobs et al. 1981) and fatigue (Horton 1982; Jacobs et al. 1981), the combination of inadequate protein intake and glycogen depletion could potentially result in reductions in strength gains that normally occur in response to resistance training.

To our knowledge, the effects of dietary restriction on resistance training-induced gains in strength have not been studied. Thus, the purpose of this study was to examine the effects of dietary restriction and subsequent body mass loss on resistance training-induced gains in strength.

\section{Methods}

Experiment design. Twenty-two obese females (body mass $=75.9 \pm 7.6 \mathrm{~kg}$; fat-free mass $=47.7 \pm 5.1 \mathrm{~kg}$; percent body fat $=37.2 \pm 7.0 ;$ age $=32.0 \pm 1.5$ years, height $=1.66 \pm 0.02 \mathrm{~m}$ ) following informed written consent, agreed to participate in an 8-week strength training study. Subjects were randomly assigned to either a diet-plus-exercise (DPE) $(n=12)$ or exerciseonly (EO) $(n=10)$ group. There were no significant differences on the pre-test for body mass, fat-free mass, fat mass and upper-arm muscle and bone area between DPE and EO.

Dietary intervention. The DPE group reduced dietary intake by 4.2 $\mathrm{MJ} /$ day on a diet that included the recommended daily allowance for vitamins, minerals and protein. A protein supplement was given to ensure protein intake $\geq 1.0 \mathrm{~g} \cdot \mathrm{kg}^{-1}$ body mass. Based on daily food records, dietary intake (including the supplement) was approximately $4.9 \pm 0.14 \mathrm{MJ} /$ day, and consisted of $27 \%$ protein, $50 \%$ carbohydrate and $23 \%$ fat. The EO group maintained normal dietary habits.

Exercise program. A Universal Power-Pac 2000 Gym was used for strength training. Following warmup, the subjects performed three sets of eight exercises (Table 1), 3 times/week, on alternate days, under trained supervision. Ten repetitions were completed in the first two sets. The subjects worked to failure (unable to voluntarily complete another repetition with a partner helping lift the mass past any momentary stoppage) in the third set. Strong verbal encouragement was provided 
Table 1. Resistance training exercises with major muscle involvement

\begin{tabular}{ll}
\hline $\begin{array}{l}\text { Resistance } \\
\text { training exercise }\end{array}$ & Major muscle involvement \\
\hline Arm curl & Biceps \\
Arm extension & Triceps \\
Bench press & Pectoralis major, triceps \\
Lateral pull-down & Latissimus dorsi, biceps \\
Leg extension & Quadriceps \\
Leg curl & Hamstrings \\
Leg press & Quadriceps, gluteals \\
Calf raise & Soleus, gastrocnemius \\
\hline
\end{tabular}

throughout by the partner and the exercise supervisor. When more than 12 repetitions could be completed in the third set, the resistance was increased. The minimum increase in resistance allowed by the apparatus was $2.3 \mathrm{~kg}$. Records were kept by the exercise supervisor of all masses lifted and repetitions completed for each individual.

The 1st training day consisted of instruction in proper lifting techniques, selection of proper 10-repetition maximum (10 $\mathrm{RM}$ ) work loads and three sets at that work load. Any under or over estimations of the $10 \mathrm{RM}$ work load were corrected prior to the next exercise session. The starting masses used for statistical analysis (week 0 ) are those of the 2 nd training day of the study.

Body composition and upper-arm muscle and bone area. The procedures used to determine body composition and upperarm muscle and bone area have been published elsewhere (Ballor et al. 1988). Briefly, body density was ascertained via hydrostatic weighing following the method of Katch et al. (1967) with a residual lung volume correction. Percent fat was calculated using the Siri formula (Siri 1961). Upper-arm muscle and bone areas were determined by analysis of radiographs taken of the right upper-arm in a horizontal position, as described by Katch and Behnke (1984). A planimeter was used to trace the muscle and bone area on the radiograph bounded by perpendicular lines drawn $10 \%$ and $80 \%$ of the longitudinal length of the humerous, starting from the distal edge.

Ten-repetition maximum changes. A 10 RM test was used to evaluate changes in strength over the 8-week training period. It was decided that testing the subjects in a manner consistent with their training regimen was more appropriate than using a 1-repetition maximum test since training adaptations have been shown to be best assessed by tests similar in nature to the method used in training (Rasch and Morehouse 1957). Thus, we have chosen to define strength as a $10 \mathrm{RM}$. We acknowledge that this definition includes a muscular endurance component. The $10 \mathrm{RM}$ represents the mass used for a particular exercise by a subject at the time of measurement.

Statistical analyses. A $2 \times 5$ (group: DPE, EO; time: weeks 0 , $2,4,6,8$ ) repeated measures ANOVA was used to test for differences between strength gains for the two groups. When significant $F$-ratios were found $(p<0.05)$, a Newman-Keuls post hoc test $(p<0.05)$ was used to determine specific mean differences. Paired and unpaired $t$-tests were used where appropriate to determine between and within group differences for body composition and upper-arm muscle and bone area comparisons. All data are presented as mean $\pm \mathrm{SD}$.

\section{Results}

Table 2 presents the pre-test, post-test and change scores for body composition. The DPE group exhibited statistically significant reductions in body mass $(-5 \%)$, and fat mass $(-14 \%)$ while the EO group did not change. Fat-free mass increased modestly for both groups, but the change did not achieve statistical significance. Both groups significantly increased their upper-arm muscle and bone area by approximately 6\%. Analysis of the change scores revealed that only the body mass and fat mass changes were different between the groups, with the DPE groups losing significantly $(p<0.05)$ more body mass and fat mass than the EO group.

The dietary restriction did not differentially affect the rate or magnitude of strength gain as evidenced by lack of statistically significant diet treatment main effects for all eight exercises $(p>0.05)$. Therefore, the two groups were combined for the purposes of analyzing adaptations

Table 2. Body mass, fat-free mass, fat mass and upper-arm area changes with resistance training (mean $\pm \mathrm{SD})$

\begin{tabular}{llrcc}
\hline Variable & Group & Pre-test & Post-test & $\begin{array}{c}\text { Post-test minus } \\
\text { Pre-test }\end{array}$ \\
\hline Body mass & & & & $-3.9 \pm 1.3^{* a}$ \\
$(\mathrm{~kg})$ & DPE & $77.5 \pm 6.1$ & $73.6 \pm 6.3$ & $0.4 \pm 2.0^{*}$ \\
Fat-free mass & EO & $73.9 \pm 10.4$ & $74.3 \pm 11.3$ & $0.5 \pm 0.9$ \\
(kg) & DPE & $47.6 \pm 4.5$ & $48.1 \pm 4.4$ & $1.1 \pm 0.8$ \\
Fat mass & EO & $47.7 \pm 5.7$ & $48.8 \pm 5.7$ & $-4.3 \pm 1.3^{* a}$ \\
$(\mathrm{~kg})$ & DPE & $29.9 \pm 7.1$ & $25.6 \pm 6.6$ & $-0.6 \pm 1.6^{*}$ \\
Upper-arm muscle & EO & $26.2 \pm 7.4$ & $25.6 \pm 8.4$ & $11.2 \pm 6.0^{\mathrm{a}}$ \\
and bone area $\left(\mathrm{cm}^{2}\right)$ & DPE & $175.8 \pm 12.2$ & $187.0 \pm 12.2$ & $10.5 \pm 6.4^{\mathrm{a}}$ \\
\hline
\end{tabular}

${ }^{a}$ Post-test significantly different from pre-test (within a group), $p<0.05$

* DPE change significantly different from EO change, $p<0.05$ 
Table 3. Changes in 10 RM during 8 weeks of resistance training exercise (mean $\pm \mathrm{SD}$ )

\begin{tabular}{|c|c|c|c|c|}
\hline Exercise & Group & Week 0 & Week 8 & $\begin{array}{l}\text { Week } 8 \text { minus } \\
\text { Week } 0\end{array}$ \\
\hline \multirow[t]{2}{*}{$\begin{array}{l}\text { Arm curl } \\
(\mathrm{kg})\end{array}$} & DPE & $\begin{array}{r}9.1 \\
+\quad 1.7\end{array}$ & $\begin{array}{r}15.4 \\
\pm \quad 2.1\end{array}$ & $6.3^{*}$ \\
\hline & $\mathrm{EO}$ & $\begin{array}{r}11.4 \\
\pm \quad 1.6\end{array}$ & $\begin{array}{r}16.1 \\
\pm \quad 1.9\end{array}$ & $4.7^{*}$ \\
\hline \multirow[t]{2}{*}{$\begin{array}{l}\text { Arm extension } \\
(\mathrm{kg})\end{array}$} & DPE & $\begin{array}{r}13.3 \\
\pm \quad 1.7\end{array}$ & $\begin{array}{r}18.6 \\
\pm \quad 1.7\end{array}$ & $5.3^{*}$ \\
\hline & EO & $\begin{array}{r}14.6 \\
+\quad 2.8\end{array}$ & $\begin{array}{r}18.5 \\
\pm \quad 2.2\end{array}$ & $3.9 *$ \\
\hline \multirow[t]{2}{*}{$\begin{array}{l}\text { Bench press } \\
\text { (kg) }\end{array}$} & DPE & $\begin{array}{r}23.3 \\
\pm \quad 3.5\end{array}$ & $\begin{array}{r}29.3 \\
\pm \quad 4.2\end{array}$ & $6.0^{*}$ \\
\hline & EO & $\begin{array}{r}26.5 \\
\pm \quad 4.7\end{array}$ & $\begin{array}{r}31.9 \\
+\quad 7.3\end{array}$ & $5.4^{*}$ \\
\hline \multirow[t]{2}{*}{$\begin{array}{l}\text { Lateral pull-down } \\
(\mathrm{kg})\end{array}$} & DPE & $\begin{array}{r}24.3 \\
\pm \quad 3.8\end{array}$ & $\begin{array}{r}34.0 \\
\pm \quad 5.5\end{array}$ & $9.7^{*}$ \\
\hline & EO & $\begin{array}{r}26.3 \\
\pm \quad 3.2\end{array}$ & $\begin{array}{r}36.7 \\
\pm \quad 6.0\end{array}$ & $10.4^{*}$ \\
\hline \multirow[t]{2}{*}{$\begin{array}{l}\text { Leg extension } \\
(\mathrm{kg})\end{array}$} & DPE & $\begin{array}{r}18.1 \\
\pm \quad 5.2\end{array}$ & $\begin{array}{r}35.9 \\
+\quad 7.6\end{array}$ & $17.8 *$ \\
\hline & EO & $\begin{array}{r}18.9 \\
\pm \quad 4.7\end{array}$ & $\begin{array}{r}36.9 \\
\pm \quad 9.5\end{array}$ & $18.0^{*}$ \\
\hline \multirow[t]{2}{*}{$\begin{array}{l}\text { Leg curl } \\
(\mathrm{kg})\end{array}$} & DPE & $\begin{array}{r}12.3 \\
\pm \quad 2.8\end{array}$ & $\begin{array}{r}18.5 \\
\pm \quad 1.7\end{array}$ & $6.2^{*}$ \\
\hline & $\mathrm{EO}$ & $\begin{array}{r}11.8 \\
\pm \quad 3.8\end{array}$ & $\begin{array}{r}18.1 \\
\pm \quad 4.1\end{array}$ & $6.3^{*}$ \\
\hline \multirow[t]{2}{*}{$\begin{array}{l}\text { Leg press } \\
(\mathrm{kg})\end{array}$} & DPE & $\begin{array}{r}62.5 \\
\pm 15.2\end{array}$ & $\begin{array}{r}121.6 \\
\pm 14.2\end{array}$ & $59.1^{*}$ \\
\hline & EO & $\begin{array}{r}66.4 \\
\pm 11.1\end{array}$ & $\begin{array}{r}124.3 \\
\pm 25.0\end{array}$ & $57.9 *$ \\
\hline \multirow[t]{2}{*}{$\begin{array}{l}\text { Calf raise } \\
(\mathrm{kg})\end{array}$} & DPE & $\begin{array}{r}64.4 \\
\pm 17.0\end{array}$ & $\begin{array}{r}137.5 \\
\pm 11.4\end{array}$ & $73.1^{*}$ \\
\hline & EO & $\begin{array}{r}68.2 \\
\pm 15.2\end{array}$ & $\begin{array}{r}128.4 \\
\pm 35.7\end{array}$ & $60.2^{*}$ \\
\hline
\end{tabular}

* Week 0 to week 8 change significantly different, $p<0.05$. Statistics are comparisons of marginal means and represent analysis of the combined scores of the groups

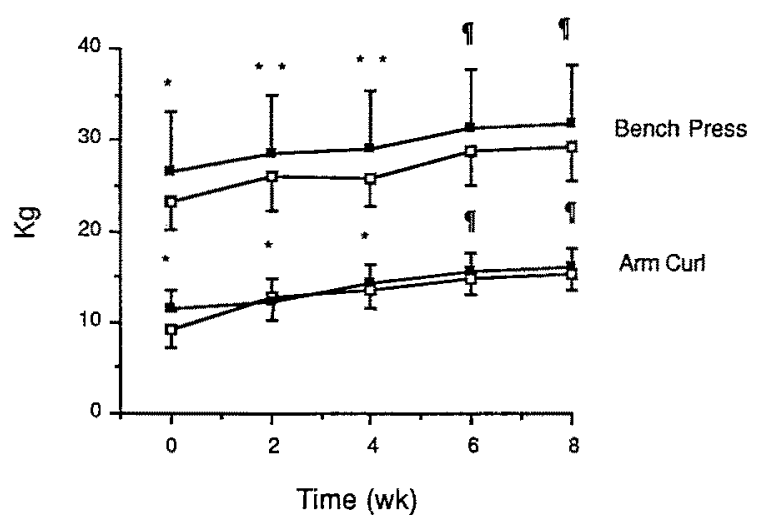

Fig. 1. Changes in arm curl and bench press 10 RM during 8 weeks of resistance training exercise. Mean $\pm S D$. Open squares, DPE. Solid squares, EO. * Significantly different from all other weeks, $p<0.05$. ** Significantly different from weeks $0,6,8, p<0.05$. Significantly different from weeks 0 , $2,4, p<0.05$. Statistics are comparisons of marginal means and represent analysis of the combined scores of the groups to training. Although the groups have been combined for the purposes of statistical analysis, the means and standard deviations of each group are included in the table and figures. Any time related comparisons (i.e., week 0 to week 8 ), however, represent changes determined by analyzing the means of the combined groups.

Table 3 contains the initial (week 0), final (week 8) and 8-week increase in $10 \mathrm{RM}$ masses for the EO and DPE groups. As might be expected, statistically significant increases in $10 \mathrm{RM}$ masses $(p<0.05)$ were found for all eight exercises. The percentage of increase in strength was smaller for the arm and trunk exercises (bench press $=23 \%$, arm extension $=33 \%$, arm curl $=52 \%$ and lateral pull-down $=41 \%$ ) then for lower body exercises (leg extension $=98 \%$, leg curl $=53 \%$, calf raise $=100 \%$ and leg press $=92 \%$ ). With the exception of the leg curl exercise, the magnitude $(\mathrm{kg})$ of all lower body changes are larger than those of the upper body exercises.

Figure 1 presents the bi-weekly changes in 10 RM for the arm curl and bench press exercises. The bi-weekly changes in $10 \mathrm{RM}$ for the other exercises are similar to those depicted in Fig. 1 and exhibit an asymptotic characteristic such that there were progressively smaller increases in strength over time. The leg press and calf raise 10 RM mass increases (not shown) were statistically different from each preceding 2 -week period $(p<0.05)$. In contrast, the $10 \mathrm{RM}$ mass increases for all other exercises (not shown) plateaued with the 6th and 8th week 10 RM training mass increases not statistically different from each other $(p>0.05)$. The data in Fig. 1 clearly show the lack of difference between the curves for the DPE and EO groups.

\section{Discussion}

Dietary restriction and body mass loss did not affect the strength gains for the obese subjects in this study. There were no statistically significant differences $(p>0.05)$ between the DPE and EO groups for any of the exercises. Apparently, for obese females, a $5 \mathrm{MJ} /$ day energy intake is sufficient to allow strength increases to take place.

The strength changes reported here are similar to those reported by others for males and females who trained but did not diet or lose body mass. Mayhew and Gross (1974) reported that $17 \mathrm{fe}$ males, following 9 weeks of resistance training, increased their $10 \mathrm{RM}$ by $5.9 \mathrm{~kg}$ and $4.8 \mathrm{~kg}$ for the bench press and arm curl, respectively. This is re- 
markably similar to the $5.7 \mathrm{~kg}$ and $5.6 \mathrm{~kg}$ found for the groups in this study. Allen et al. (1976) reported $8 \mathrm{RM}$ increases for men that were larger in magnitude than those of the current study but slightly smaller as a percentage of starting value (leg $\operatorname{curl}=27 \%$, bench press $=44 \%$, leg press $=71 \%$ ).

The asymptotic nature of the strength increases reflects a combination of neural and muscular adaptations. Initial rapid gains followed by slower sustained increases in strength have been reported previously and are thought to represent, first, neurally mediated increases in strength followed by slower muscle growth-induced strength gains (Hakkinen and Komi 1983). Increases in muscle mass following resistance training were found for the females in this study using X-ray (Table 2) and by others using computer-aided tomography (Cureton et al. 1988). Thus, our data are consistent with rapid initial neural adaptations followed by a slower muscle growth component.

Other measures of maximum performance also do not seem to be affected by moderate dietary restrictions in lean or obese individuals. For example, Hagan et al. (1986) examined the effects of a $5.0 \mathrm{MJ}$ intake on changes in $\dot{V}_{\mathrm{O}_{2}}$ maximum during 12 weeks of aerobic training for 96 obese men and women. Although the diet-restricted men and women lost $12 \%$ and $10 \%$ of their body mass, respectively, their improvement in $\dot{V}_{\mathrm{O}_{2}}$ maximum $\left(1 \cdot \min ^{-1}, \mathrm{ml} \cdot \mathrm{min}^{-1} \cdot \mathrm{kg}-\mathrm{FFM}^{-1}\right)$ was the same as that of the obese men and women undergoing the same training protocol without body mass loss. Finally, McMurray et al. (1985) found no decrement in $\dot{V}_{\mathrm{O}_{2}}$ maximum following 7 days of $4.2 \mathrm{MJ} /$ day dietary restriction in six lean endurance training males.

In summary, it is apparent that dietary restriction and subsequent body mass loss had little affect on the rate of strength gain for the obese women in this study. Apparently, in the mildly obese female, those factors responsible for stimulating muscle strength gains operate during moderate boy mass loss (via diet and exercise). This may not be the case for normal or underweight individuals undergoing reductions in dietary intake, since a greater stress may be placed on protein reserves of lean individuals who may not have adequate fat reserves to supply all the necessary energy. For example, Keys et al. (1950) reported reductions of approximately $29 \%$ in maximal fore- arm and back strength for normal weight males losing $24 \%$ of their body weight over 24 weeks.

It would appear, based on the present study, that $10 \mathrm{RM}$ strength can improve in moderately obese females who undergo moderate dietary restriction and body mass loss.

\section{References}

Allen TE, Byrd RJ, Smith DP (1976) Hemodynamic consequences of circuit weight training. Res 47:299-306

Aoki TT (1981) Metabolic adaptations to starvation, semi-starvation, and carbohydrate restriction. In: Selvey N, White PL (eds) Nutrition in the 1980s: constraints on our knowledge. A. R. Liss, New York, pp 161-177

Ballor DL, Katch VL, Becque MD, Marks CR, Nau KL (1988) Resistance weight training during caloric restriction enhances lean body weight maintenance. Am J Clin Nutr $47: 19-25$

Cureton KJ, Collins MA, Hill DW, McElhannon FM (1988) Muscle hypertrophy in men and women. Med Sci Sports Exerc 20:338-344

Hagan RD, Upton SJ, Wong L, Whittam J (1986) The effects of aerobic conditioning and/or caloric restriction in overweight men and/or women. Med Sci Sports Exerc 18:87-94

Hakkinen K, Komi P (1983) Electromyographic changes during strength training and detraining. Med Sci Sports Exerc $15: 455-460$

Horton ES (1982) Effects of low energy diets on work performance. Am J Clin Nutr 35:1228-1233

Jacobs I, Kaiser P, Tesch P (1981) Muscle strength and fatigue after selective glycogen depletion in human skeletal muscle fibers. Eur J Appl Physiol 46:47-53

Katch FI, Michael ED, Horvath SM (1967) Estimation of body volume by underwater weighing: a description of a simple method. J Appl Physiol 23:811-813

Katch FI, Behnke AR (1984) Arm X-ray assessment of percent fat in men and women. Med Sci Sports Exerc 16:316-321

Keys A, Brozek J, Henschel A, Mickelsen O, Taylor HL (1950) The biology of human starvation, vol 1. University of Minnesota Press, Minneapolis

Mayhew JL, Gross PM (1974) Body composition changes in young women with high resistance weight training. Res $Q$ 45:433-440

McMurray RG, Ben-Ezra V, Forsythe WA, Smith AT (1985) Responses of endurance-trained subjects to caloric deficits induced by diet or exercise. Med Sci Sports Exerc 17:574-579

Rasch PJ, Morehouse LE (1957) Effect of static and dynamic exercise on muscular strength and hypertrophy. J Appl Physiol 11:29-34

Siri WE (1961) Body composition from fluid spaces and density. In: Brozek J, Henshel A (eds) Techniques for measuring body composition. National Academy of Sciences, Washington, DC, pp 223-244

Accepted June 22, 1989 